\title{
A sensibilidade à flor da pele
}

\author{
Heightened sensitivity
}

\author{
Marco Antonio Arantes \\ Professor adjunto da Universidade Estadual do Oeste do Paraná. \\ marcoarantes@hotmail.com
}

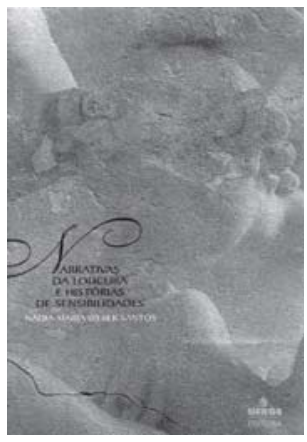

SANTOS, Nádia Maria Weber. Narrativas da loucura e história de sensibilidades. Porto Alegre: Editora da Universidade Federal do Rio Grande do Sul, 2008. 320 p.
$\mathrm{F}$ alaremos, a princípio, de três personagens. O primeiro: T.R., um paciente anônimo internado em 1937 no hospital psiquiátrico São Pedro de Porto Alegre por gostar de muito ler e escrever. T.R. tinha ideias boas e interessantes para a pequena fábrica de sabão anticaspa da família, que era de relativas posses e de origem alemã. Suas ideias, no entanto, eram vistas pelos seus pais como coisas estranhas e extravagantes, típicas de um homem com mania de grandeza. O hospício foi o seu destino. Lá, escreveu muitas cartas, nenhuma tratada como material literário, mas sim como sintomas de um transtorno mental, rabiscos irracionais e incompreensíveis de um louco. Outro personagem: Lima Barreto, um dos grandes expoentes da literatura nacional no início do século XX, autor de Triste fim de Policarpo Quaresma. Lima Barreto sucumbiu ao preconceito racial e ao desprezo de grande parte da crítica literária, restando-lhe bebedeiras incomensuráveis que o conduziriam a caminhadas desvairadas a esmo pelas ruas da antiga capital do país. Estigmatizado como louco, passou duas estadas no Hospício Nacional, a primeira em 1914, e a segunda em 1919. O terceiro personagem: Rocha Pombo, historiador-filólogo, professor, poeta e jornalista paranaense, autor de História da América. Amante da leitura e da escrita, nunca foi considerado um louco, mas um autor que escreveu sobre a loucura em seu romance simbolista No hospício, publicado em 1905. Era um intelectual com grandes projetos, ainda que muitos deles não se concretizassem em sua época, como a criação de uma universidade no Paraná, que oferecesse cursos de direito, letras, comércio, agronomia, agrimensura e farmácia.

Para T.R., foi destinado o diagnóstico de parafrenia, uma síndrome de delírios crônicos. Para Lima Barreto, um tratamento purgativo à base de poção gomosa de ópio para curarlhe as alucinações e delírios decorrentes do alcoolismo. A Rocha Pombo, por sua vez, a angústia de nunca ser reconhecido como escritor, a miséria batendo à sua porta e o pesado fardo de sustentar oito filhos no Rio de Janeiro com um mísero salário de professor.

Esses são os três personagens da obra Narrativas da loucura e histórias de sensibilidades, da historiadora, médica e psiquiatra de orientação junguiana Nádia Maria Weber Santos. Sua grandeza repousa na exímia sensibilidade com que a autora analisa romances, diários e 
cartas desses três autores. Nádia Weber Santos evoca o embate presente nas sensibilidades desses três personagens, nos limites tênues da razão e da desrazão. Trata-se de uma das obras mais interessantes e originais sobre o tema da loucura dos últimos anos, quando a intertextualidade se faz presente na interpretação de obras.

O projeto de Nádia Weber Santos, fruto de sua tese de doutorado em história na Universidade Federal do Rio Grande do Sul, tem como ponto de referência a sensibilidade expressa nas vivências, nas representações e na ficção desses três autores. A obra inicia com um estudo sobre as relações entre literatura e loucura, abordando 'loucos' ou não loucos que escreveram sobre a experiência da loucura. A autora apoia-se, sobretudo, em pesquisas advindas da sociologia da leitura, nas teorias sobre a escrita e leitura de Jacques Leenhardt, para mostrar que a imaginação é um componente essencial na interpretação do mundo.

Há uma preocupação em humanizar e dar sentido a essas falas silenciadas e excluídas. Com efeito, a autora divide sua obra em quatro capítulos. No primeiro, "Andanças pelo tempo e pelo espaço: a loucura e o hospício em diversas narrativas", debruça-se sobre o conceito de sensibilidade, sobre a realidade sensível da 'alma' do louco, definindo-o como uma instância relativa às questões subjetivas, sentidas e vivenciadas pelo ser humano. Nádia Weber Santos percorre uma vasta produção de narrativas sobre e da loucura, delineando desde o imaginário presente na mitologia grega até as noções de sensibilidade atuais. Seu ponto de referência é a sensibilidade expressa na escrita e na produção literária desses autores, que descortina com maestria à luz das teorias da psicologia analítica formuladas no século XX por Jung, para quem "a origem de toda a criatividade humana está no inconsciente, naquela parte ainda desconhecida da psique humana, e que pertence a toda humanidade, não a uma pessoa específica" (citado na p.303). A autora serve-se ainda da psicologia analítica de Jung para mergulhar fundo no imaginário presente nos gêneros literários, nas narrativas do sensível, para ressaltar que o imaginário é carregado de símbolos, imagens e fantasias humanas, "cujo conteúdo, emprego ou serventia são específicos ou estranhos, indicando um sentido oculto, obscuro e desconhecido" (p.49).

Mas não é somente em Jung que Nádia Weber se apoia. Novamente Leenhardt é uma referência analítica quando se resgata a escrita de T.R. e Lima Barreto, ou mesmo a fala do narrador do romance No hospício, de Rocha Pombo, com suas representações da loucura numa ficção dentro da ficção. Ao utilizar Leenhardt e Jung, a autora prende-se ao aspecto simbólico das cartas, diários e textos literários, para assim extrair as sensações, o sentido e o imaginário desses 'loucos' escritores. Assim, faz uma leitura do delírio como registro autêntico e carregado de sentidos, uma leitura em direção ao símbolo, desnudando escritos que são coerentes por si mesmos e não simples manifestações de síndromes e doenças. Nádia procura, portanto, o sentido no 'eu', e dá voz ao que é silenciado, arquivado e enclausurado nas paredes dos hospícios aos cuidados de médicos como Jacintho Godoy, diretor do Hospital Psiquiátrico São Pedro de Porto Alegre por vinte anos, o que nos faz lembrar da frase de Jurandir Freire Costa (s.d., p.63): "o médico tornou-se sacerdote do corpo e o médico-psiquiatra, em particular, do espírito".

No segundo capítulo, "Doze cartas e um versinho: o tempo de T.R. no hospício (1937): um escritor 'engavetado', anonimato e ressentimento", a autora faz a leitura das cartas do paciente T.R., escritas quando estava internado no Hospital Psiquiátrico São Pedro de 
Porto Alegre. Pouco se sabe da vida de T.R., a não ser pelas cartas e pelos prontuários médicos, que detalhavam seu estado psíquico e faziam referência à sífilis e a sua transferência para a Seção de Terapêutica. Ao que tudo indica, T.R. foi submetido à terapêutica psiquiátrica da malarioterapia. Era um leitor fascinado pela figura do intelectual gaúcho Vianna Moog, autor de Novas cartas persas, seu principal interlocutor e a quem endereçava a maioria das cartas sobre questões políticas e sociais. T.R. também escrevia poesia e falava de temas religiosos, sexuais, comerciais e filosóficos. Nesses escritos percebe-se um talento literário podado e silenciado por um saber médico, que o tornou inaudível e ininteligível para a maioria das pessoas; assim como se construiu e se domesticou uma personalidade amarga e carregada de ressentimentos em relação aos familiares que o internaram por entender que ler e escrever muito eram coisas de louco. Aqui é importante compreender o sentido das cartas que nunca eram enviadas, mas arquivadas no próprio hospício como documentação médica. Eram cartas que continham "imagens, símbolos, metáforas, carregadas de significados de uma vida, de uma época" (p.139). Deve-se ressaltar a importância do estudo histórico feito pela autora sobre o olhar lançado a esses 'escritos especiais', e a menção aos Annalles médico-psychologiques, de Henri Legrand du Saulle, como uma referência na psiquiatria na sistematização teórica sobre o sentido dos escritos dos doentes mentais. Segundo Nádia Santos, tais estudos de Legrand "confirmavam ou traíam por eles mesmos a existência e a natureza do delírio".

De uma maneira mais ampla, segundo a autora, três olhares paralelos interpretaram o sentido das cartas ao longo da história: o primeiro procurava identificar sinais de loucura nos escritos, tais como tendências para atos violentos, até mesmo para o suicídio; o segundo olhar tendia a fazer testes científicos sobre esses escritos a fim de criar um saber autônomo sobre a escritura; e um terceiro olhar se fixava no aprendizado do ato de escrever e no desenvolvimento da estenografia.

No terceiro capítulo, "O tempo de Lima Barreto no Diário de hospício e Cemitério dos vivos (1920): um escritor na contramão da história", a autora analisa a calvário vivido no hospício pela figura talvez mais emblemática do livro: o romancista carioca Afonso Henriques de Lima Barreto. Ela se apoia em duas importantes obras que tratam do tema da loucura: as anotações do Diário de hospício e o romance inacabado Cemitério dos vivos, consideradas as últimas obras do escritor. Alteridade e loucura estão presentes nessas duas obras, e os acontecimentos descritos são dimensionados como ressonâncias do 'eu' do autor, que permitem a compreensão de sua personalidade literária. A primeira obra diz respeito a anotações feitas durante as duas internações no Hospício Nacional e a reflexões significativas acerca da loucura e dos loucos, o corpo administrativo e os médicos que o examinaram no hospício. A segunda obra é um romance confessional, uma mistura de ficção e realidade, que foi elaborada tendo como roteiro de referência o Diário de hospício. Há também referências a outros dois romances do escritor, como Triste fim de Policarpo Quaresma e Recordações do escrivão Isaías Caminha, e um importante estudo sobre a vivência da loucura em seu meio familiar, com a reconstrução dos momentos que marcam os primeiros contatos de Lima Barreto, na infância, com loucos; contatos que têm início na Colônia de Alienados da Ilha do Governador, local de trabalho de seu pai. 
Esse mesmo universo é ampliado com a desgraça familiar: a morte precoce da mãe; a loucura paterna, que o acompanhou até o fim; o contato com os amigos loucos; as tensões profissionais; e, por fim, o alcoolismo, que o conduziria a duas internações no Hospício Nacional (Arantes, 2008). A percepção da própria loucura, tanto em Lima Barreto como em T.R., é a de não se deixar convencer do diagnóstico de loucura por uma ciência caduca e avessa à sensibilidade dos pacientes, mesmo que em alguns momentos fossem favoráveis a um tratamento médico.

Constata-se, a partir da obra de Santos, que o desenvolvimento da segregação nos hospícios no início do século XX serviu para calar as vozes dos doentes mentais de forma brutal e impiedosa, sob os auspícios de uma psiquiatria saturada de conotações ideológicas.

Por fim, o quarto capítulo, "O tempo de Rocha Pombo e o seu romance no hospício (1905): miséria humana e espírito livre", é um estudo sobre o romance psicológico No hospício, do historiador Rocha Pombo. Para Nádia Santos, o escritor "assume o discurso do louco: a subjetividade do escritor mesclando-se à subjetividade do personagem-narrador, que se finge louco para poder entrar no manicômio" (p.222), e nesse ponto aproxima-se da proposta de Lima Barreto; embora este não tenha se fingido de louco para entrar no manicômio, reconstrói sua experiência mesclando dados reais e inventados em uma ficção.

Segundo a autora, pouco se sabe sobre as motivações que levaram Rocha Pombo a escrever o romance, pois ele nada escreveu sobre o assunto. Em nenhum artigo, carta ou estudo discute as técnicas literárias e a estrutura dramática utilizadas na composição do romance. Tampouco o porquê da escolha do tema. O mesmo aconteceu com a crítica literária do período, com raras exceções, como a de Massaud Moisés, que se referiu ao livro como um exemplo acabado de teoria de história da arte simbolista. O que ficou foi um dos romances mais interessantes sobre o tema da loucura, mesmo levando-se em conta a imagem estereotipada do louco recorrente na época. Por outro lado, segundo a autora, o romance prima por "fragilizar a barreira existente entre sanidade e loucura. Página após página as palavras são testemunho disto" (p.259-260). E talvez seja essa a grande contribuição de Nádia Santos, ao nos colocar na tênue fronteira entre a razão e a desrazão.

\section{REFERÊNCIAS}

ARANTES, Marco Antonio. Estranhos interiores: a loucura em Triste fim de Policarpo Quaresma. Psicologia em Estudo, Maringá, v.13, n.4, p.875-883. 2008.
COSTA, Jurandir Freire. História da psiquiatria no Brasil: um corte ideológico. Rio de Janeiro: Xenon. s.d. 